\title{
BMJ Open Is tuberculosis health education reaching the public in China? A cross- sectional survey in Guizhou Province
}

\author{
Wei Chen, ${ }^{1}$ Yang Li, ${ }^{1}$ Haiqin Yang, ${ }^{2}$ John Ehiri, ${ }^{3}$ Zaiping Chen, ${ }^{1}$ Ying Liu, ${ }^{2}$ \\ Mei Wang, ${ }^{2}$ Shili Liu, ${ }^{2} \mathrm{He}$ Tang, ${ }^{4}$ Ying $\mathrm{Li}^{2}$
}

To cite: Chen W, Li Y,

Yang $\mathrm{H}$, et al. Is tuberculosis health education reaching the public in China? A crosssectional survey in Guizhou Province. BMJ Open 2016;6: e013534. doi:10.1136/ bmjopen-2016-013534

- Prepublication history and additional material is available. To view please visit the journal (http://dx.doi.org/ 10.1136/bmjopen-2016013534).

WC and YaL contributed equally.

Received 20 July 2016 Accepted 2 September 2016

CrossMark

For numbered affiliations see end of article.

Correspondence to

Dr He Tang;

466174@qq.com and

Dr Ying Li;

lilyliying2012@163.com

\section{ABSTRACT}

Background: Knowledge about tuberculosis (TB) is important for TB control, and China's national TB control guidelines emphasise TB health promotion. A 2010 national TB epidemiology survey showed that the general public had limited knowledge and awareness of TB.

Objective: To assess the level of TB knowledge after 5 years of TB health promotion in Guizhou Province, one of the regions with the highest TB burden in China.

Design and setting: A community-based, crosssectional survey of 10237 residents of Guizhou Province from June to August 2015. Multiple logistic regression models were used to examine factors associated with core TB knowledge and TB health education among respondents.

Results: Overall, residents of Guizhou Province had inadequate knowledge of TB. The overall awareness of TB was $41.5 \%$. Less than $30 \%$ of respondents were familiar with China's policy of free treatment for TB or knew that the disease could be cured. Factors associated with core TB knowledge included gender, age, ethnicity, education, occupation, region, and having received TB health education. Women, older adults, people employed in non-government institutions, and those living in counties with low TB burdens had little access to TB health education, whereas people with higher education levels had greater access. Respondents' sources of TB knowledge did not necessarily match their preferred channels for delivery of TB health education.

Conclusions: Our findings indicate that TB health education should be further strengthened in China and other countries with a high TB burden. TB health education programmes require further formative and implementation research in order to improve programme effectiveness.

\section{INTRODUCTION}

The incidence of tuberculosis (TB) has been slowly declining each year and it is estimated that 37 million lives were saved globally between 2000 and 2013 through effective

\section{Strengths and limitations of this study}

- This study provides empirical data to assess changes in tuberculosis (TB) knowledge among residents of Guizhou Province, at the end of the 2010-2015 national TB control plan in the province.

- In addition to assessing core TB knowledge among residents of Guizhou Province, this study also assessed community health education needs, and explored the preferred channels for delivery of TB health education.

- TB health promotion and education are intended to improve knowledge and awareness, and also to engender behaviour change for TB prevention and improvement of treatment outcomes through adherence. A limitation of this study is that it assessed only community knowledge and awareness; it did not explore the relationship between such knowledge and TB-related behaviour change.

diagnosis and treatment. ${ }^{1}$ The millennium development goal (MDG) target of a falling TB incidence rate by 2015 has already been met globally. However, the MDG targets of halving TB prevalence and mortality rates globally by 2015, compared with a baseline of 1990, remain unmet. ${ }^{1}$ Progress towards targets for the response to multidrug-resistant $\mathrm{TB}$ (MDR-TB) set out in the Global Plan to Stop TB 2011-2015 is also not on track. ${ }^{1}$ A WHO report in 2015 indicated that China still had the second highest number of cases ( $11 \%$ of the global total), with a high burden of MDR-TB despite international and national efforts to deal with TB in the country. ${ }^{1}$

Ample evidence has shown that patient delay in seeking treatment, delayed diagnosis and treatment, and patient non-compliance with treatment remain a problem for $\mathrm{TB}$ control in China. ${ }^{2-4}$ Lack of knowledge about $\mathrm{TB}$ is an important cause of delays in seeking healthcare, diagnosis, and treatment, ${ }^{56}$ which increases the risk of $\mathrm{TB}$ transmission and the 
development of MDR-TB. ${ }^{4}$ The Chinese government has therefore focused on improving the public's knowledge about TB, and the State Council has issued a 10-year National Plan to Control TB, with one indicator of its success assessment of public TB knowledge. The National Plan to Control TB 2001-2010 required $80 \%$ of the public to possess some knowledge of TB by the end of $2010{ }^{7}$ the target for the 2011-2015 national plan was $85 \%$ by the end of $2015 .^{8}$ TB health education was emphasised in the 2006 and 2008 National Guidelines for TB Control, requiring TB health promotion to be carried out among patients with $\mathrm{TB}$, patient contacts, the public, students, migrant workers, health policy makers, and health workers. ${ }^{9} 10$ To evaluate the impact of TB health education, surveys of TB knowledge have been conducted nationally and locally, particularly at the end of each 10-year national plan. At the end of the 2001-2010 national TB control plan, the 5th National TB Survey was also conducted, to evaluate public knowledge. ${ }^{3}$

The end of 2015 is significant, representing a transition between the MDG established in 2000 and a post-2015 development framework. ${ }^{1}$ It is also important for China because 2015 is the final year of the 12th 5-year plan. China has initiated assessment of the achievements in every area, and evaluation of TB control is required in all regions of China. Guizhou Province in southwest China has a high TB burden and low levels of socioeconomic development. ${ }^{11} 12$ The results of a survey of TB knowledge among residents of Guizhou, which was conducted in 2015, are reported here. It is hoped that these findings can help to identify whether the information is reaching the targets and if current TB health education methods meet the needs of residents. This will serve as a base for improving efforts to strengthen TB education in the region and similar locations in low- and middle-income countries with a high TB burden.

\section{METHODS}

Study design and setting

We conducted a cross-sectional study in Guizhou Province from June to August 2015. Guizhou is located in southwest China, and has a population of 352022 million. The province is a historically impoverished and ecologically fragile mountainous region with a rich diversity of minority groups. Guizhou is typical of many such less developed inland provinces, with a relatively large population living in poverty ${ }^{13} 14$ and is one the regions of China with a high TB burden. The fifth national TB epidemiological survey in 2010 indicated that the average TB prevalence (per 100000 ) in Guizhou was 1226, which is much higher than the national level (459) and also higher than that in western China (695). ${ }^{3} 15$ The number of new patients with $\mathrm{TB}$ in Guizhou ranges from 40000 to 50000 . The incidence of TB in the province has decreased since 2012 but is ranked the third highest in China after Xinjiang Province and Tibet (unpublished data). The prevalence of acquired MDR-TB cases in Guizhou is much higher $(45.1 \%)$ than the national average $(25.6 \%){ }^{11}$

\section{Study population and sampling}

A stratified random sample was used to select appropriate study areas, as follows. First, all counties and districts in Guizhou Province were grouped into three levels according to their ranking of TB incidence in 2014: (1) high-level TB burden (TB incidence in the highest $30 \%$ ); (2) low-level TB burden (TB incidence in the lowest 30\%); and (3) mid-level TB burden (TB incidence in the remaining $40 \%$ ). Three counties or districts were then randomly selected from those with high and low TB burdens, and four counties or districts randomly selected from those with mid-level TB burdens. A total 10 counties and districts were selected. Finally, one community from each county or district was randomly selected as a study location. A total 10 communities were selected as the final study areas. One thousand residents from each community were randomly selected as study participants. People in the study communities who met the following criteria were included in the survey: aged $\geq 15$ years; lived in the study place for more than half a year. People who could not express themselves clearly (who had disturbance of consciousness or difficulties with speech or hearing) and who were unwilling to participate in the survey were excluded. During recruitment, we explained the study objectives in detail to potential participants, who were then asked if they would be interested in participating in the survey. The informed consent form included information about ensuring that confidentiality was given to those who agreed to participate. Consent forms were then signed as confirmation of participants' voluntary participation.

\section{Questionnaire}

A standardised questionnaire (questionnaire on TB core knowledge, which was compiled by the National Center for Tuberculosis Control and Prevention, Chinese Center for Disease Control and Prevention) (see online supplementary data 1) was used to collected data from all counties and districts. It included the following: (1) questions on sociodemographic profile (age, sex, occupation, ethnicity, education, county, or district of residence); (2) five questions covering core TB knowledge areas including: (i) classic TB symptoms such as coughing up blood-tinged sputum, (ii) TB modes of transmission, (iii) curability of TB, (iv) location of, and services provided by, local TB dispensaries, and (v) the national free TB treatment policy; (3) questions about receiving $\mathrm{TB}$ health education, methods of obtaining knowledge about TB, and participants' preferred sources of TB information. It was pilot tested with 150 participants and assessed for validity and reliability. We used explanatory factor analysis to analyse the construct validity of the questionnaire and Cronbach's $\alpha$ coefficient to determine the internal reliability of questionnaire by SPSS V.18.0 (Chicago: SPSS, Chicago, Illinois, USA). The results 
showed Kaiser-Meyer-Olkin (KMO) measure $=0.74$, Bartlett's test $=21188.253, \mathrm{df}=10, \mathrm{p}<0.001$. Cronbach's $\alpha$ coefficient was 0.801 . The results indicated that the validity and reliability of the questionnaire was acceptable.

All questionnaires were administered by trained investigators recruited from among local TB health workers in villages or communities throughout the province.

\section{Ethical considerations}

The study was approved by the China National Ethics Committee of Operational Research on TB, and the Center of Disease Control and Prevention of Guizhou Province.

\section{Data analysis}

EpiData V.3.1 was used for data entry, and SPSS V.18.0 was used to analyse the data. Missing data were excluded from the analysis. Percentages were used to describe the characteristics of study subjects. To assess TB knowledge among respondents, the percentage of people who provided correct responses to each question on core knowledge about TB was calculated. Overall awareness about TB was calculated as follows:

\section{$\sum$ No. of correct answers to}

the five questions (on core TB knowledge) $\frac{\text { of all participants, TB knowledge per person }}{\text { No. of questionnaires } \times 5} \times 100 \%$

Percentages were used to describe sources of TB knowledge and the preferred source for delivery of TB health education among respondents. We used $\chi^{2}$ statistics to assess participants' responses by county or district, sex, age, education, occupation, and ethnicity. Multiple logistic regression models were used to examine factors associated with core TB knowledge (correct answer=1, incorrect answer $=0$ ) and having received TB health education (yes $=1, \mathrm{no}=0$ ) among respondents. A two-tailed probability level of $<0.05$ was used as the level of statistical significance.

\section{RESULTS}

This study was conducted in three counties with a high incidence of TB (Nayong, Luodian, and Zhoutaijiang counties), four with mid-level TB incidence (Dejiang, Ziyun, and Zunyi counties and Huairen District), and three districts with low TB incidence (Zhouxinyi, Baiyun, and Zhongshan districts) (figure 1). A total of 10643 community members were asked to participate in the survey, but 375 declined and 10268 finally completed the survey questionnaire (response rate 96.5\%). Thirty-one migrant participants were excluded from the final analysis, according to our inclusion criteria. Thus, data from 10237 participants were included in the analysis.

\section{Respondent characteristics}

Demographic characteristics of participants are presented in table 1 . Of the participants, $57.7 \%$ were female. All respondents were aged $\geq 15$ years, but most were between 30 and 70 years old $(75.6 \%)$. A total of
Figure 1 Map of Guizhou area, China, where the study took place. The coloured areas indicate the sampling regions: red, counties with a high-level burden of TB; blue, middle-level TB burden; green, low-level TB burden.

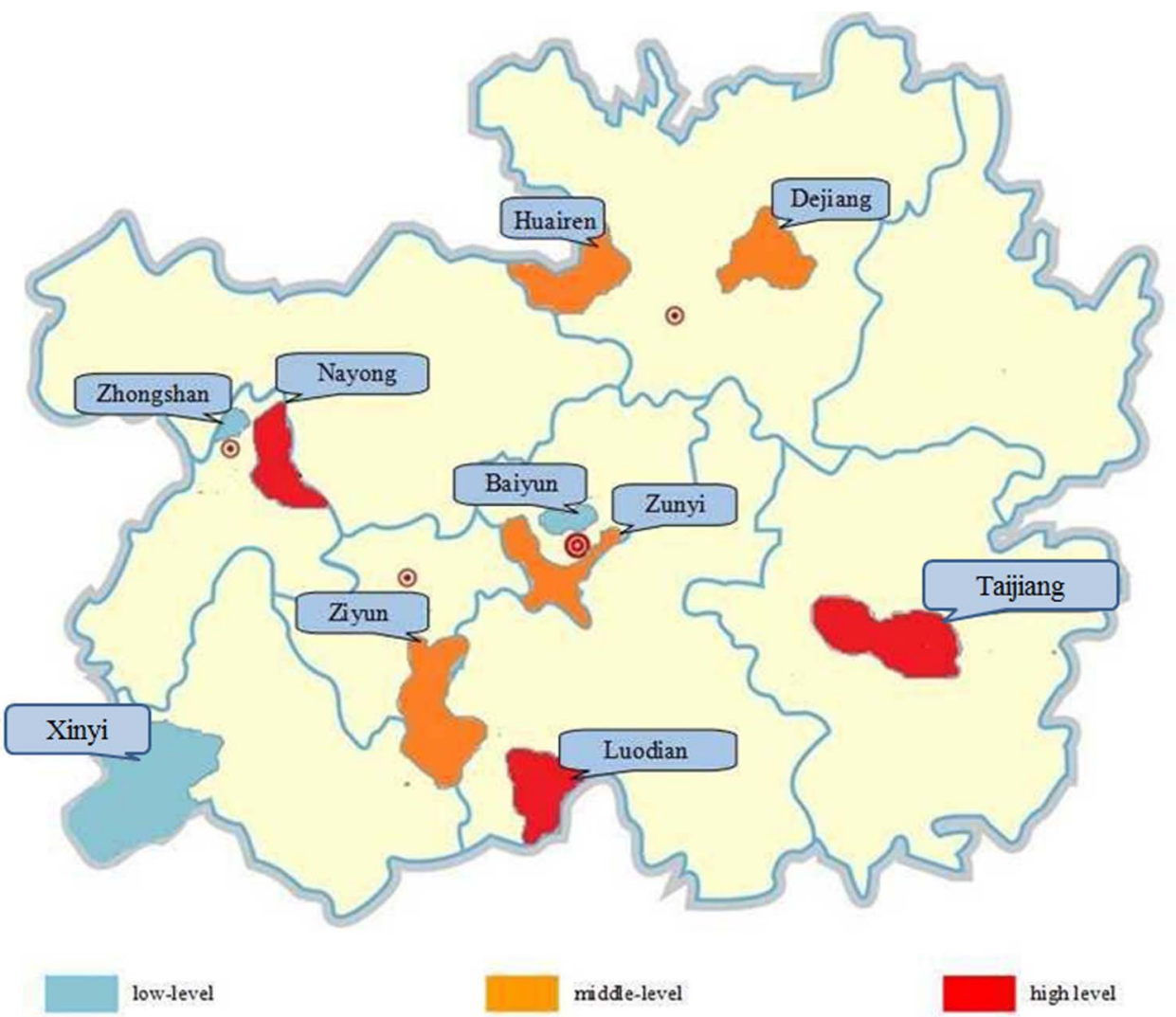


$56.5 \%$ had Han ethnicity. More than $90 \%$ of participants had a junior middle school level of education or below. The majority of respondents were peasant farmers. Residents from counties with high, middle, and low TB burdens comprised $30.3 \%, 39.6 \%$, and $30.1 \%$ of respondents, respectively. Notably, only $35.1 \%$ of participants had previously received TB health education.

\section{Core TB knowledge and TB health education}

The overall TB core knowledge rate was $41.5 \%$. For each item of core TB knowledge, about half of respondents had some knowledge of $\mathrm{TB}$ signs and symptoms $(58.3 \%)$, routes of $\mathrm{TB}$ transmission $(50.1 \%)$, and local TB health facilities $(46 \%)$. However, less than one-third of survey respondents knew that TB is a curable disease $(28.8 \%)$ and that anti-TB drugs are provided free of charge in China (24.2\%) (figure 2A). It is notable that only $8.7 \%$ of respondents gave correct answers to all five

\begin{tabular}{|c|c|c|}
\hline Characteristics & Number & Percentage \\
\hline \multicolumn{3}{|l|}{ Gender (N=10 235) } \\
\hline Male & 4326 & 42.3 \\
\hline Female & 5909 & 57.7 \\
\hline \multicolumn{3}{|l|}{ Age $(\mathrm{N}=10230)$} \\
\hline$<30$ & 1389 & 13.6 \\
\hline $30-40$ & 1439 & 14.1 \\
\hline $40-50$ & 2622 & 25.6 \\
\hline $50-60$ & 1821 & 17.8 \\
\hline $60-70$ & 1851 & 18.1 \\
\hline$>70$ & 1108 & 10.8 \\
\hline \multicolumn{3}{|l|}{ Ethnicity (10 228) } \\
\hline Han & 5777 & 56.5 \\
\hline Bouyei & 1268 & 12.4 \\
\hline Miao & 1466 & 14.3 \\
\hline Tujia & 894 & 8.7 \\
\hline Others & 823 & 8.0 \\
\hline \multicolumn{3}{|l|}{ Education ( $\mathrm{N=10} 234$ ) } \\
\hline Illiteracy & 3644 & 35.6 \\
\hline Primary and below & 3123 & 30.5 \\
\hline Junior middle school & 2572 & 25.1 \\
\hline $\begin{array}{l}\text { Senior middle school and } \\
\text { above }\end{array}$ & 895 & 8.7 \\
\hline \multicolumn{3}{|l|}{ Occupation ( $\mathrm{N}=10236)$} \\
\hline Government & 303 & 3.0 \\
\hline Enterprise & 378 & 3.7 \\
\hline Students & 709 & 6.9 \\
\hline Peasants & 7343 & 71.7 \\
\hline Retired & 135 & 1.3 \\
\hline Others & 1368 & 13.4 \\
\hline \multicolumn{3}{|l|}{ Counties/districts ( $N=10$ 236) } \\
\hline High level TB burden & 3102 & 30.3 \\
\hline Middle level TB burden & 3043 & 29.7 \\
\hline Low level TB burden & 3080 & 30.1 \\
\hline District under province & 1011 & 9.9 \\
\hline \multicolumn{3}{|c|}{ Receipt of TB health education ( $N=10218)$} \\
\hline Yes & 3590 & 35.1 \\
\hline No & 6628 & 64.9 \\
\hline
\end{tabular}

questions, and $26.4 \%$ had no knowledge about TB whatsoever (figure 2B).

Results of a $\chi^{2}$ test are shown in table 2 and results of multiple logistic regression analysis are presented in table 3. More men than women had some core TB knowledge for all items, except curability, and results of multiple logistic regression analysis also found women had poor TB knowledge for all items except for curability. The percentages of participants who had TB knowledge for all items decreased with age and increased with education level, except for China's free-service TB treatment policy. Multiple logistic regression analysis confirmed that higher educational level was related to greater TB knowledge for all items, but participants aged $\geq 40$ years had better knowledge of China's free treatment policy.

More minority participants had knowledge of signs and symptoms and curability of $\mathrm{TB}$, but Han participants had better knowledge of the local appointed TB health facility. Multiple logistic regression analysis confirmed that those ethnic minorities had better knowledge of the signs and symptoms of TB and curability of TB, but had poor knowledge of routes of TB transmission and local appointed TB health facilities.

For occupation, respondents who worked in government institutions had greater knowledge of all items on TB, except for the free TB treatment policy, but multiple logistic regression analysis found that participants from enterprise, retired people, and other participants had poor knowledge of the signs and symptoms of TB and routes of TB transmission, students had poor knowledge of local TB health facilities and curability of TB, peasants had better knowledge of the free TB treatment
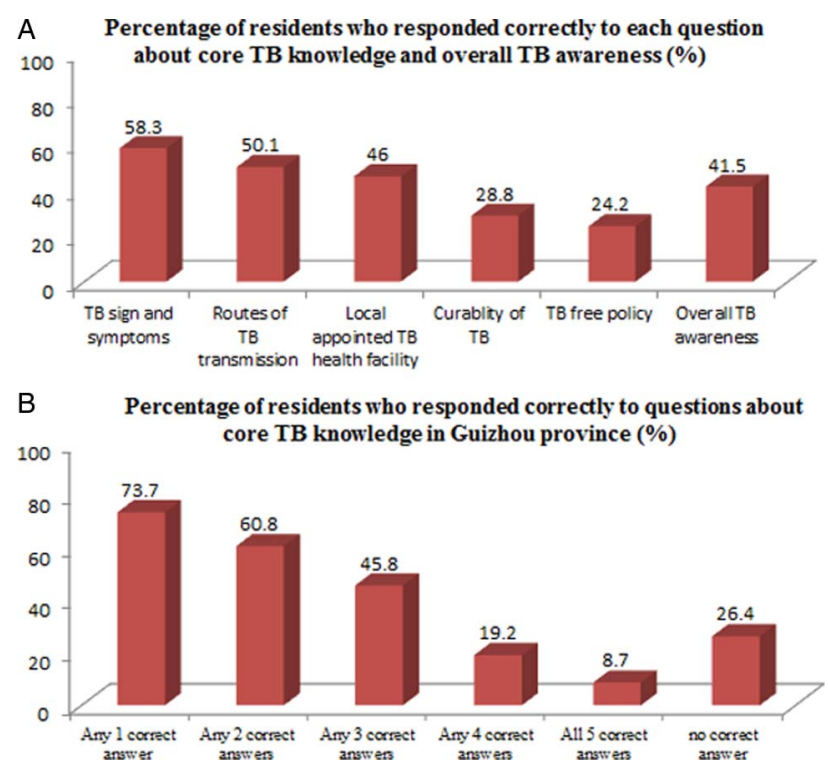

Figure 2 Percentage of residents in Guizhou province, China, with core TB knowledge. (A) Percentage correctly answering each item of core TB knowledge. (B) Percentage answering no questions or correctly answering up to five questions about core TB knowledge. 
Table 2 Distribution of core knowledge of TB and receipt of TB health education by demographic characteristics in Guizhou province $†$

\begin{tabular}{|c|c|c|c|c|c|c|}
\hline Characteristics & $\begin{array}{l}\text { TB signs and } \\
\text { symptomsN (\%) }\end{array}$ & $\begin{array}{l}\text { Routes of TB } \\
\text { transmissionN (\%) }\end{array}$ & $\begin{array}{l}\text { Local appointed TB } \\
\text { health facilityN (\%) }\end{array}$ & $\begin{array}{l}\text { Free TB treatment } \\
\text { policyN (\%) }\end{array}$ & $\begin{array}{l}\text { Curability of } \\
\text { TBN (\%) }\end{array}$ & $\begin{array}{l}\text { Receipt of TB } \\
\text { health education }\end{array}$ \\
\hline \multicolumn{7}{|l|}{ Gender } \\
\hline Male & $2702(62.5)$ & 2403 (55.5) & $2129(49.2)$ & $1053(24.3)$ & $1213(28.0)$ & $1761(40.7)$ \\
\hline Female & $3280(55.5)^{\star}$ & $2743(46.4)^{\star}$ & $2591(43.8)^{*}$ & $1421(24.0)$ & 1733 (29.3) & $1828(30.9)^{\star}$ \\
\hline \multicolumn{7}{|l|}{ Age } \\
\hline$<30$ & $1038(75.2)$ & $970(70.2)$ & $823(59.6)$ & 267 (19.3) & 441 (31.9) & 727 (52.8) \\
\hline $30-40$ & $938(65.6)$ & $829(58.0)$ & 752 (52.6) & $304(21.3)$ & $428(29.9)$ & $632(44.3)$ \\
\hline $40-50$ & 1540 (58.9) & 1337 (51.1) & $1272(48.6)$ & $668(25.5)$ & $757(28.9)$ & $941(36.0)$ \\
\hline $50-60$ & 1003 (55.2) & $829(45.6)$ & $790(43.5)$ & $454(25.0)$ & $522(28.7)$ & $553(30.5)$ \\
\hline $60-70$ & 947 (51.2) & 761 (41.2) & 696 (37.7) & 505 (27.3) & 509 (27.5) & 485 (26.3) \\
\hline$>70$ & $494(44.7)^{\star}$ & $397(35.9)^{\star}$ & $372(33.6)^{\star}$ & $266(24.1)^{\star}$ & $281(25.4)^{\star}$ & $240(21.7)^{\star}$ \\
\hline \multicolumn{7}{|l|}{ Ethnicity } \\
\hline Han & 3277 (56.7) & 2907 (50.3) & $2880(49.9)$ & $1402(24.3)$ & $1297(22.5)$ & $1837(31.8)$ \\
\hline Minority & $2702(60.7)^{*}$ & $2236(50.2)$ & $1836(41.2)^{*}$ & $1072(24.1)$ & $1648(37.0)^{*}$ & $1753(39.4)^{*}$ \\
\hline \multicolumn{7}{|l|}{ Education } \\
\hline Illiteracy & 1507 (41.4) & 1155 (31.7) & 1194 (32.8) & $769(21.1)$ & 964 (26.5) & 818 (22.4) \\
\hline Primary school & $1836(58.8)$ & $1561(50.0)$ & $1441(46.1)$ & $843(27.0)$ & 868 (27.8) & 1045 (33.5) \\
\hline Junior middle school & $1879(73.1)$ & $1697(66.0)$ & 1445 (56.2) & $684(26.6)$ & $774(30.1)$ & $1154(44.9)$ \\
\hline $\begin{array}{l}\text { Senior middle school } \\
\text { and above }\end{array}$ & $761(85.0)^{*}$ & $733(81.9)^{*}$ & $641(71.6)^{*}$ & $178(19.9)^{*}$ & $341(38.1)^{\star}$ & $572(63.9)^{*}$ \\
\hline \multicolumn{7}{|l|}{ Occupation } \\
\hline Government & $254(83.8)$ & $242(79.9)$ & $204(67.3)$ & 49 (16.2) & 119 (39.3) & 220 (72.6) \\
\hline Enterprise & $240(63.5)$ & $214(56.6)$ & $203(53.7)$ & $62(16.4)$ & $155(41.0)$ & $210(55.6)$ \\
\hline Students & 516 (72.8) & 491 (69.3) & 384 (54.2) & $126(17.8)$ & 201 (28.3) & 384 (54.2) \\
\hline Peasants & 4279 (58.3) & 3601 (49.0) & 3275 (44.6) & $1981(27.0)$ & 2097 (28.6) & 2379 (32.4) \\
\hline Retired & 66 (48.9) & $59(43.7)$ & $54(40.0)$ & $21(15.6)$ & $33(24.4)$ & $50(37.0)$ \\
\hline Others & $628(45.9)^{\star}$ & $540(39.5)^{*}$ & $601(43.9)^{*}$ & $236(17.3)^{\star}$ & $342(25.0)^{\star}$ & $347(25.4)^{\star}$ \\
\hline \multicolumn{7}{|l|}{ Counties/districts } \\
\hline $\begin{array}{l}\text { High level TB } \\
\text { burden }\end{array}$ & $1833(59.1)$ & $1359(43.8)$ & $878(28.3)$ & $433(14.0)$ & $1122(36.2)$ & $1244(40.1)$ \\
\hline $\begin{array}{l}\text { Middle level TB } \\
\text { burden }\end{array}$ & 2177 (71.5) & $2034(66.8)$ & $2113(69.4)$ & $1330(43.7)$ & $1174(38.6)$ & $1190(39.1)$ \\
\hline Low level TB burden & $1465(47.6)$ & $1232(40.0)$ & $1631(53.0)$ & $408(13.2)$ & $516(16.8)$ & $708(23.0)$ \\
\hline District under province & $508(50.2)^{\star}$ & $522(51.6)^{*}$ & $99(9.8)^{\star}$ & $304(30.1)^{*}$ & $135(13.4)^{*}$ & $448(44.3)$ * \\
\hline \multicolumn{7}{|c|}{ Receipt of TB health education ( $\mathrm{N}=10$ 237) } \\
\hline Yes & $2936(81.8)$ & $2729(76.0)$ & $2316(64.5)$ & $910(25.3)$ & $1282(35.7)$ & - \\
\hline No & $3037(45.8)^{*}$ & $2406(36.3)^{*}$ & $2397(36.2)^{\star}$ & $1560(23.5)^{*}$ & $1659(25.0)^{*}$ & - \\
\hline
\end{tabular}


Table 3 Factors associated with the core knowledge of tuberculosis (TB) and receipt of TB health education among residents in Guizhou province

\begin{tabular}{|c|c|c|c|c|c|c|}
\hline \multirow[b]{2}{*}{ Factors } & \multicolumn{6}{|l|}{ OR (95\% Cl) } \\
\hline & $\begin{array}{l}\text { TB sign and } \\
\text { symptoms }\end{array}$ & $\begin{array}{l}\text { Routes of TB } \\
\text { transmission }\end{array}$ & $\begin{array}{l}\text { Local appointed TB } \\
\text { health facility }\end{array}$ & $\begin{array}{l}\text { Free TB treatment } \\
\text { policy }\end{array}$ & Curability of TB & $\begin{array}{l}\text { Receipt of TB health } \\
\text { education }\end{array}$ \\
\hline \multicolumn{7}{|l|}{ Gender ( $N=10235)$} \\
\hline Male & Reference & Reference & Reference & Reference & Reference & Reference \\
\hline Female & $0.89(0.81$ to 0.98$)$ & $0.80(0.73$ to 0.88$)$ & $0.85(0.77$ to 0.94$)$ & 0.88 (0.79 to 098$)$ & 1.29 (1.17 to 1.42$)$ & $0.84(0.76$ to 0.92$)$ \\
\hline \multicolumn{7}{|l|}{ Age $(\mathrm{N}=10230)$} \\
\hline$<30$ & Reference & Reference & Reference & Reference & Reference & Reference \\
\hline $30 \sim 40$ & $1.01(0.83$ to 1.22$)$ & 0.97 (0.80 to 1.18$)$ & 0.81 (0.64 to 1.02$)$ & 1.15 (0.93 to 1.42$)$ & 0.98 (0.82 to 1.18$)$ & $1.00(0.85$ to 1.19$)$ \\
\hline $40-50$ & $1.00(0.83$ to 1.20$)$ & 0.94 (0.79 to 1.12$)$ & $0.94(0.77$ to 1.16$)$ & $1.52(1.25$ to 1.85$)$ & $1.10(0.93$ to 1.31$)$ & $0.83(0.70$ to 0.97$)$ \\
\hline $50-60$ & 1.03 (0.85 to 1.25$)$ & $0.86(0.71$ to 1.04$)$ & 0.98 (0.82 to 1.18$)$ & 1.47 (1.19 to 1.80$)$ & 1.20 (1.00 to 1.44$)$ & 0.63 (0.53 to 0.75$)$ \\
\hline $60-70$ & $1.11(0.90$ to 1.35$)$ & $0.88(0.72$ to 1.08$)$ & $1.10(0.91$ to 1.33$)$ & 1.69 (1.36 to 2.10$)$ & $1.14(0.94$ to 1.39$)$ & $0.54(0.45$ to 0.65$)$ \\
\hline$>70$ & $1.00(0.80$ to 1.24$)$ & 0.84 (0.68 to 1.05$)$ & 1.24 (0.98 to 1.56$)$ & 1.48 (1.16 to 1.88$)$ & $1.00(0.80$ to 1.25$)$ & 0.45 (0.36 to 0.55$)$ \\
\hline \multicolumn{7}{|l|}{ Ethnicity (10 228) } \\
\hline Han & Reference & Reference & Reference & Reference & Reference & Reference \\
\hline Minority & $1.24(1.10$ to 1.39$)$ & $0.78(0.69$ to 0.87$)$ & $0.56(0.50$ to 0.63$)$ & 0.95 (0.85 to 1.07$)$ & 1.34 (1.20 to 1.49$)$ & 1.21 (1.09 to 1.36$)$ \\
\hline \multicolumn{7}{|c|}{ Education $(\mathrm{N}=10234)$} \\
\hline Illiteracy & Reference & Reference & Reference & Reference & Reference & Reference \\
\hline Primary school & 2.20 (1.96 to 2.47$)$ & 2.08 (1.85 to 2.34$)$ & 1.79 (1.58 to 2.03$)$ & 1.52 (1.34 to 1.73$)$ & 1.21 (1.07 to 1.37$)$ & 1.48 (1.32 to 1.67$)$ \\
\hline $\begin{array}{l}\text { Junior middle } \\
\text { school }\end{array}$ & 4.34 (3.75 to 5.02$)$ & 3.96 (3.43 to 4.58$)$ & 2.74 (2.36 to 3.19$)$ & 1.81 (1.55 to 2.12$)$ & 1.30 (1.13 to 1.50$)$ & 2.01 (1.75 to 2.30$)$ \\
\hline $\begin{array}{l}\text { Senior middle } \\
\text { school and above }\end{array}$ & 7.88 (6.15 to 10.10$)$ & $8.31(6.55$ to 10.54$)$ & 7.06 (5.57 to 8.95$)$ & 1.83 (1.44 to 2.32$)$ & 1.73 (1.40 to 2.13$)$ & 3.36 (2.75 to 4.11$)$ \\
\hline \multicolumn{7}{|c|}{ Occupation $(\mathrm{N}=10236)$} \\
\hline Government & Reference & Reference & Reference & Reference & Reference & Reference \\
\hline Enterprise & $0.55(0.35$ to 0.84$)$ & $0.57(0.38$ to 0.86$)$ & $1.12(0.76$ to 1.64$)$ & $1.20(0.77$ to 1.86$)$ & $2.06(1.46$ to 2.91$)$ & $0.72(0.50$ to 1.03$)$ \\
\hline Students & $0.69(0.46$ to 1.05$)$ & $0.81(0.55$ to 1.20$)$ & $0.68(0.48$ to 0.97$)$ & $0.90(0.60$ to 1.34$)$ & 0.67 (0.49 to 0.93$)$ & $0.52(0.38$ to 0.72$)$ \\
\hline Peasants & $0.88(0.60$ to 1.28$)$ & $0.87(0.61$ to 1.24$)$ & $1.15(0.84$ to 1.58$)$ & 1.56 (1.09 to 2.23$)$ & $0.83(0.63$ to 1.11$)$ & $0.36(0.27$ to 0.48$)$ \\
\hline Retired & $0.42(0.24$ to 0.72$)$ & $0.48(0.28$ to 0.81$)$ & $0.60(0.35$ to 1.01$)$ & 0.93 (0.52 to 1.69$)$ & 1.13 (0.69 to 1.87$)$ & $0.54(0.34$ to 0.87$)$ \\
\hline Others & $0.48(0.32$ to 0.71$)$ & $0.52(0.36$ to 0.75$)$ & $0.82(0.59$ to 1.15$)$ & $1.27(0.87$ to 1.85$)$ & $1.12(0.83$ to 1.52$)$ & $0.27(0.20$ to 0.37$)$ \\
\hline \multicolumn{7}{|c|}{ Counties/districts ( $\mathrm{N}=10236)$} \\
\hline $\begin{array}{l}\text { High level TB } \\
\text { burden }\end{array}$ & Reference & Reference & Reference & Reference & Reference & Reference \\
\hline $\begin{array}{l}\text { Middle level TB } \\
\text { burden }\end{array}$ & 1.67 (1.48 to 1.89$)$ & 3.02 (2.67 to 3.42$)$ & 7.59 (6.65 to 8.65$)$ & 4.60 (4.03 to 5.24$)$ & $1.28(1.14$ to 1.43$)$ & 1.05 (0.94 to 1.18$)$ \\
\hline $\begin{array}{l}\text { Low level TB } \\
\text { burden }\end{array}$ & 0.61 (0.53 to 0.70$)$ & 0.95 (0.82 to 1.10$)$ & 3.42 (2.95 to 3.96$)$ & $0.92(0.77$ to 1.09$)$ & $0.40(0.35$ to 0.46$)$ & $0.46(0.40$ to 0.53$)$ \\
\hline $\begin{array}{l}\text { District under } \\
\text { province }\end{array}$ & $0.45(0.37$ to 0.54$)$ & 1.15 (0.96 to 1.39$)$ & $0.13(0.10$ to 0.17$)$ & 2.39 (1.96 to 2.90$)$ & $0.30(0.24$ to 0.38$)$ & 1.64 (1.37 to 1.96$)$ \\
\hline \multicolumn{7}{|c|}{ Receipt of TB health education $(\mathrm{N}=10237)$} \\
\hline No & Reference & Reference & Reference & Reference & Reference & - \\
\hline Yes & 4.37 (3.94 to 4.88$)$ & 4.63 (4.19 to 5.13$)$ & 4.87 (4.35 to 5.45$)$ & 0.98 (0.88 to 1.09$)$ & 1.41 (1.28 to 1.56$)$ & - \\
\hline
\end{tabular}


policy, and participants from enterprise had better knowledge of the curability of TB.

Residents of counties and districts with a mid-level TB burden had the most ТB knowledge, whereas those from counties and districts with low TB burdens had the least information about all items, except for local TB health facilities and this was confirmed by multiple logistic regression analysis. Participants from counties and districts with a low TB burden had poor knowledge of signs and symptoms and curability of $\mathrm{TB}$ and better knowledge of local appointed TB health facilities, and residents in a district under province had poor knowledge of TB signs and symptoms, local appointed TB health facilities and curability of TB, but better knowledge of free policy. All survey respondents who had received TB health education had greater knowledge, except for the TB free policy. Multiple logistic regression analysis showed that having received previous TB health education was associated with better knowledge of all items, except for China's free TB treatment policy $(\mathrm{OR}=0.98$ (95\% CI 0.88 to 1.09$)$ ).

In addition, we observed that study participants who were male, younger, more educated, better employed, and from a district under province had the most opportunities to receive TB health education (table 2). Multiple logistic regression analysis similarly showed that women, the aged, and those employed in nongovernment institutions, living in counties with low TB burdens had less accessibility to TB education, but that educated, people with minority ethnicity and residents in a district under province had better accessibility to TB health education (table 3 ).

\section{Sources of TB knowledge}

Responses to our survey indicated that the most common source of information about TB was television $(32.1 \%)$, the second was relatives and friends $(30.4 \%)$ and leaflets $(30.4 \%)$, the third was education provided by a health worker (29.8\%), and the fourth most common source was education delivered by community leaders $(24.8 \%$ ) (figure 3). However, we found that common methods used to deliver health education, such as posters, exhibits, banners, billboards, school health education, free medical consultations, and health lectures, did not reach the targets expected.

\section{Preferred sources of TB knowledge}

The most preferred methods for obtaining knowledge about TB were education provided by health workers $(61.3 \%)$; this was followed by television broadcasts, movies, websites, or videos $(40.7 \%)$. Less preferred sources of knowledge included education provided by community leaders $(35.6 \%)$; chatting with relatives and friends $(22.3 \%)$; and posters, exhibits, banners, or billboards (18.2\%). Commonly used by health educators, leaflets were preferred by only $10.7 \%$ of survey respondents. Additionally, $11.3 \%$ and $7.6 \%$ of participants preferred newspapers or magazines and school health education, respectively, for obtaining knowledge about TB (figure 4).

Participants' preferred materials for imparting ТВ knowledge were brochures with pictures $(30.1 \%)$, audiovisual products $(23.4 \%)$, text-only brochures $(15.9 \%)$, and the internet $(5.9 \%)$. However, close to $40 \%$ of participants had no specific preference (figure 5).

\section{DISCUSSION}

A lack of knowledge about TB among the general public is a continuing problem in China, and a barrier to its control. ${ }^{3}$ National and local TB programmes have endeavoured to promote public knowledge about the disease and national and local surveys were recently conducted to evaluate public TB awareness across China, particularly at the end of the 10-year National Plan to Control TB (2001-2010) (unpublished material). ${ }^{16-29}$ These surveys showed poor TB awareness among the public in most regions. Exceptions included the districts of Pingliang in Gansu Province and Tongling City in Anhui Province, which reported overall awareness of TB of $80.3 \%{ }^{17}$ and $78.7 \%,{ }^{18}$ respectively. The 5th National TB Epidemiology survey in 2010 showed that only $57 \%$ of the population had adequate TB knowledge. ${ }^{16}$ Surveys conducted in 2010 in more developed regions of the country showed an overall awareness of TB of $45.66 \%$ in Zhejiang Province ${ }^{19}$ and $52.9 \%$ in Shenzhen
Figure 3 Major sources of TB knowledge among residents in Guizhou province, China.

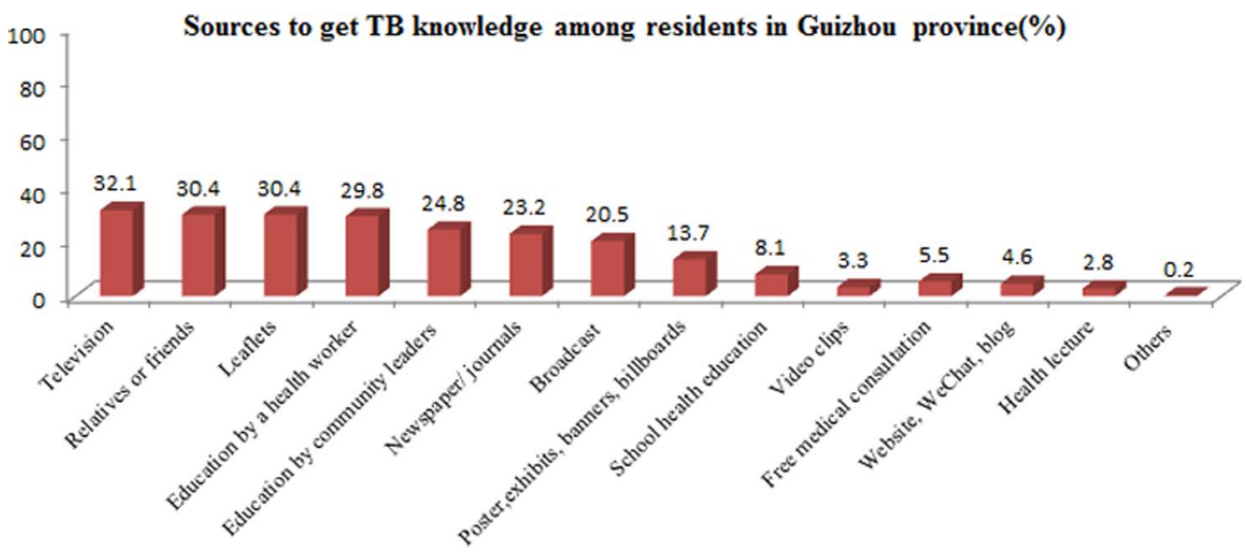


Figure 4 Preferred source of TB knowledge among residents in Guizhou province, China.

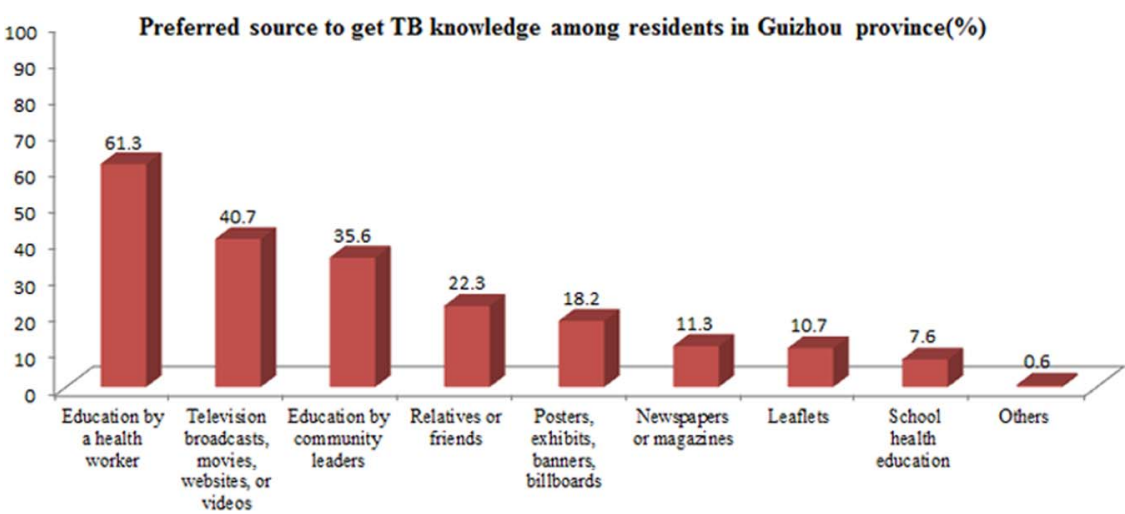

District in Guangdong Province ${ }^{20}$ which are far below the $80 \%$ level required by the 2001-2010 National Plan. ${ }^{7}$ The overall awareness of $\mathrm{TB}$ in southwest China reported in 2010 was even lower, with $44.2 \%$ in Gongga, Tibet $^{21}$ and $33.31 \%$ in Guizhou Province. ${ }^{22}$

The new National Plan to Control TB (2011-2015) was completed in 2015. Our survey found that the overall public awareness of TB in Guizhou Province was $41.5 \%$, which is an improvement on the 2010 survey results $(33.31 \%)$. Nevertheless, this is far below the requirement for $85 \%$ according to this new National Plan. Our survey also found that $26.4 \%$ of residents in Guizhou had no core knowledge of TB. We also found that $<30 \%$ of study participants knew about the policy for free $\mathrm{TB}$ treatment or about the curability of $\mathrm{TB}$; these results were lower than those of the 2010 survey (33.4\% for the free treatment policy and $29.3 \%$ for curability) in this province. ${ }^{22}$ Our survey found that men had greater TB knowledge than women in Guizhou. This is consistent with previous surveys in other regions of China, ${ }^{19} 20$ 23-26 which suggests that women should be a target population for the promotion of TB health education. Core knowledge about TB in Guizhou decreased with age, similar to previous surveys in Shenzhen, Wuhan, and Guangzhou. ${ }^{20} 2526$ We also observed that people with higher levels of education had greater TB knowledge, which is also consistent with previous reports in Zhejiang, Jiangsu, and Gansu. ${ }^{17} 1928$ These results may partly explain why older adults and people with lower education levels are often susceptible to TB. Only $35.1 \%$ of respondents had ever received TB health education. Inadequate TB health education is probably the main reason for the low public awareness of $\mathrm{TB}$ in China's Guizhou Province.

This study and previous reports ${ }^{30} 31$ showed that health education has a major role in improving $\mathrm{TB}$ knowledge and awareness, health-seeking behaviour, and adherence to treatment, thus reducing the incidence of drug-resistant TB and TB infection. The Chinese government has actively promoted health education. The Practical Toolkit for promotion of TB control and prevention was issued by the Chinese Center for Disease Control and Prevention of the Ministry of Health Foreign Loan Office in 2005. ${ }^{32}$ The Guidelines on Enforcement of the Chinese Tuberculosis Control Program issued in 2006 and 2008 include a chapter on TB health promotion and provide an indicator of $\mathrm{TB}$ core knowledge for target participants, to assess its implementation. ${ }^{9}{ }^{10}$ In addition, the guidelines specify five items of core knowledge about TB. ${ }^{9}{ }^{10}$ A series of health promotion and health education activities have been carried out across China in recent years. However, public awareness about TB has not improved substantially and remains far below the requirements of the National Guideline, as discussed above. This survey also found that residents of Guizhou Province with lower socioeconomic status (women, older adults, the employed in non-government institutions, and people with lower education levels) had less access to TB health education, excluding the $35.1 \%$ of participants who had previously received such education. Hence, reassessment health education for populations at different socioeconomic levels is advisable. of ways to improve access to, and effectiveness of, TB
Figure 5 Preferred method of delivery of TB knowledge among residents in Guizhou province, China.

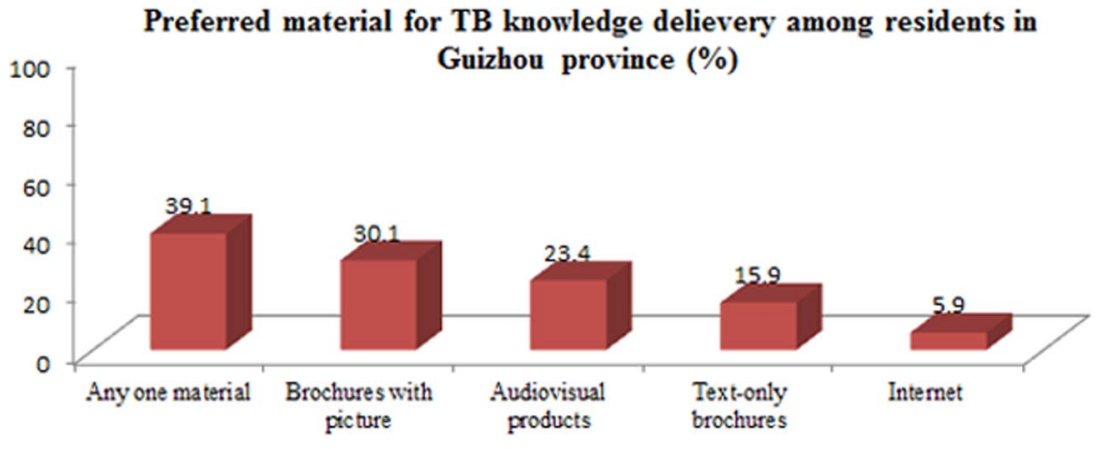


For health education, certain modes of communication are more useful for particular groups than others. ${ }^{33}$ Conducting a needs assessment is vital to understand the target population, such as the prior population and preferred mode of communication for a specific group, so as to develop more effective strategies. ${ }^{33}{ }^{34}$ However, few studies have paid sufficient attention to an assessment of needs. Our study found that disadvantaged people (women, those with less education, and older or underemployed adults) have more limited access to TB health education and for them, developers of education programmes should rethink their approach.

A few studies have investigated the sources of knowledge about TB. ${ }^{21} 272935{ }^{36}$ For example, one survey in the city of Chongqing reported that the three main sources of information were relatives or others $(66.9 \%)$; television, websites, films, and other similar media $(41.7 \%)$; and posters, exhibits, billboards, and other printed materials $(30.48 \%) .{ }^{27}$ A survey in Jilin Province found that leaflets $(50.28 \%)$, newspapers and magazines $(46.6 \%)$, and relatives or others $(22.94 \%)$ were the main sources. ${ }^{29}$ In Gongga, Tibet, the main sources were education provided by health workers $(44.30 \%)$, followed by information from relatives or others $(36.50 \%),{ }^{21}$ and in Inner Mongolia, television $(65.6 \%)$ and other people $(47.2 \%) .{ }^{35}$ Our survey found these sources to be television, followed by relatives and friends, information from leaflets, education provided by health workers, and last, information provided by community leaders. These results demonstrate that the main sources for obtaining information about TB vary by region and across different populations in China.

A few studies have investigated the preferred means and channels for delivery of TB health education. We found that most respondents preferred education provided by health workers; this was followed by information obtained via television, websites, films, and similar media; education by community leaders; and the least preferred method was information received from relatives or friends. As in previous studies, ${ }^{37}$ our survey showed that the common methods used to deliver health education are not necessarily preferred by the target population.

Although the National Guidelines for TB Control in China emphasise the need for promotion of TB health education to the public, it is likely that such education is largely ineffective owing to a lack of knowledge of the needs of the target populations. Our results suggest that research into TB health education, including the most effective methods and sources for imparting such education for specific populations, should be undertaken.

\section{Limitations and implications}

This study provides empirical data to enable assessment of changes in TB knowledge among residents of Guizhou Province, at the end of the 2010-2015 National TB Control Plan in the province. In addition to assessing core TB knowledge among residents of Guizhou Province, this study also assessed community health education needs, and explored the channels for delivery of TB health education preferred by the community.

However, this study has a number of limitations. First, more questions are required to identify the preferred health education communication mode for populations with different characteristics in order to provide evidence for policy making. Second, we collected data by questionnaire alone rather than using both quantitative and qualitative research methods, which would have provided a deeper understanding of the factors associated with poor TB awareness and the TB health education needs of different communities. Last, TB health promotion and education are intended to influence behavioural change, and encourage the public to take appropriate measures to prevent $\mathrm{TB}$ infection and improve their adherence to treatment. ${ }^{16}$ It is best to combine core knowledge assessment with evaluation of behavioural change using behaviour indicators ${ }^{38}$ to assess the impact of $\mathrm{TB}$ health promotion and education.

To design more effective and feasible TB health education programmes for specific target populations, formative research ${ }^{39} 40$ and implementation research ${ }^{41}$ to improve programme designs are warranted. First, formative research should be concerned with using participatory research methods and mixed research methods (other than a questionnaire alone) to collect data. ${ }^{40}$ Second, based on the results of formative research, designing health programmes using participatory methods ${ }^{42}$ would improve their acceptability among all populations. Third, implementation research is needed to improve implementation strategies of evidence-based TB health education programmes.

\section{CONCLUSION}

Public awareness of TB is low in Guizhou Province, China. Evidence from this survey indicates that accessing TB health education is a possible, effective means to improve core TB knowledge. All opportunities to use health education to raise the public awareness about TB should be taken advantage of in countries with high TB burdens. However, the effectiveness of TB health education programmes should be explored by conducting formative and implementation research so as to improve programme designs.

\section{Author affiliations}

${ }^{1}$ Department of Tuberculosis Control, Center of Disease Control and Prevention, GuiYang, China

${ }^{2}$ Department of Social Medicine and Health Service management, Third Military Medical University, Chongqing, Chongqing, China

${ }^{3}$ Mel \& Enid Zuckerman College of Public Health, Division of Health Promotion Sciences, University of Arizona, Tucson, Arizona, USA ${ }^{4}$ Department of Hygienic Toxicology, Third Military Medical University, Chongqing, China

Acknowledgements The authors thank the participants who responded to our questionnaires. We also thank Edanz Editing China for language editing. 
Contributors YLi and HT designed this survey; WC, YaL, ZC collected data and control quality of data collection; WC,YLiu, SL and MW managed data, $\mathrm{HY}$ and YLi analyzed data. YLi and JE drafted the manuscript. JE edit the manuscript. All authors interpreted the results, revised the report and approved the final version.

Funding This research received no specific grant from any funding agency in the public, commercial or not-for-profit sectors.

Competing interests None declared.

Patient consent Obtained.

Ethics approval The study was approved by the China National Ethics Committee of Operational Research on TB, and the Center of Disease Control and Prevention of Guizhou Province.

Provenance and peer review Not commissioned; externally peer reviewed.

Data sharing statement No additional data available.

Open Access This is an Open Access article distributed in accordance with the Creative Commons Attribution Non Commercial (CC BY-NC 4.0) license which permits others to distribute, remix, adapt, build upon this work noncommercially, and license their derivative works on different terms, provided the original work is properly cited and the use is non-commercial. See: http:// creativecommons.org/licenses/by-nc/4.0/

\section{REFERENCES}

1. WHO. Global tuberculosis report 2015. http://apps.who.int/iris/ bitstream/10665/191102/1/9789241565059_eng.pdf?ua=1

2. Li Y, Ehiri J, Tang S, et al. Factors associated with patient, and diagnostic delays in Chinese TB patients: a systematic review and meta-analysis. BMC Med 2013;11:156.

3. Wang Y. Report of the Fifth National Sampling Survey of TB Epidemiology. Beijing: Military Medical Science Press; 2011: $1-7$

4. Liang $L, W u Q$, Gao L, et al. Factors contributing to the high prevalence of multidrug-resistant tuberculosis: a study from China. Thorax 2012:67:632-8.

5. Li Y, Ehiri J, Oren E, et al. Are we doing enough to stem the tide of acquired MDR-TB in countries with high TB burden? Results of a mixed method study in Chongqing, China. PLOS ONE 2014;9: e88330.

6. Tolossa D, Medhin G, Legesse M. Community knowledge, attitude, and practices towards tuberculosis in Shinile town, Somali regional state, eastern Ethiopia: a cross-sectional study. BMC Public Health 2014;14:804.

7. MOH. National plan to control TB. 2001-2010. http://www.gov.cn/ gongbao/content/2001/content_61160.htm

8. People's Republic of China State Council. National plan to control TB 2011-2015, China. http://www.gov.cn/zwgk/2011-12/06/content 2012869.htm

9. Center for Disease Control in China. The operational guideline for tuberculosis control program in China. Beijing: Ministry of Health 2006.

10. Center for Disease Control in China. The operational guideline for Tuberculosis control program in China. Beijing: Ministry of Health, 2008.

11. Chen L, Li N, Liu M, et al. High prevalence of multidrug-resistant tuberculosis in Zunyi, Guizhou Province of China. J Antimicrob Chemother 2011;66:2435-7.

12. Chen $\mathrm{HJ}$, Chen $\mathrm{P}, \mathrm{Yang} \mathrm{J}$, et al. Analysis of tuberculosis epidemics in Guizhou Province between 2005 and 2012. Modem Prev Med 2015;42:342-4.

13. Wo TC. Exploring sustainable tourism development in mountainous Guizhou Province, China. J Hospitality Manag Tourism 2015;6:60-70.

14. Wu Z, Wang LJ. On rural tourism resource development in Guizhou. $\mathrm{http}: / /$ www.seiofbluemountain.com/upload/product/200910/ 2009glhy14a6.pdf

15. Chen HJ, Yang J, Yuan W, et al. Analysis of the result of epidemiological survey on tuberculosis in Guizhou Province. Modern Prev Med 2013;40:1214-15.

16. $Y u$ L, Lv Q, Xia YY, et al. The National awareness survey on key TB messages in 2010. Chin J Antituberculosis 2013;1:60-4.
17. Ma $X Y$, Ji XF, Zhang $X X$, et al. Survey and analysis on public knowledge about Pingliang TB control. Chin Primary Health Care 2012;26:68-70.

18. Chen QL, Chen MT, Lv Q, et al. Survey on knowledge, attitude and practice for tuberculosis control and impact factors among residents in Tongling City of Anhui Province. Chin J Health Educ 2013;29:305-8.

19. Huang $\mathrm{Y}$, Zhong JM, Chen $\mathrm{SH}$, et al. Investigation analysis on public awareness of tuberculosis knowledge in Zhejiang province, 2010. Zhonghua Yu Fang Yi Xue Za Zhi 2012;46:352-4.

20. Lv JW, Yang YZ, Lv DL, et al. Analysis of public awareness rate of tuberculosis in Shenzhen. Chin J Antituberculosis 2011;33:295-8.

21. Suolang ZX, Yang Z. Awareness of tuberculosis knowledge in Gonggar County. Parasitoses Infect Dis 2013;11:81-3.

22. Chen HJ, Pan JM, Yang J. TB knowledge in 5 epidemiology survey sites in Guizhou province. Guizhou Med J 2011;35:278-80.

23. Li F, Wang WX, Song CY, et al. Analysis on the awareness status of knowledge on tuberculosis prevention and control among residents, Shangdong Province. Prev Med Trib 2014;20:8-10, 19.

24. Li XQ, Wang CP. Analysis of survey on public knowledge of tuberculosis prevention and control in Shanxi province. J Pract Med Tech 2011;18:798-9.

25. Du J, Hu J, Tian D, et al. A survey on TB knowledge in Wuhan. J Clin Hematol 2012;25:250-1.

26. Jiang L, Zhong Q, Li JW, et al. Analysis of public awareness rate of tuberculosis control and prevention in Guangdong province. Chin $J$ Antituberculosis 2012;12:813-16.

27. Yi j, Hu DY, Liu Y, et al. Awareness status of relevant knowledge on pulmonary tuberculosis of residents in Chongqing. Chin Gen Pract 2012;15:1498-500.

28. Wang XS, Chang $\mathrm{XH}$, Guo HJ, et al. Analysis of public knowledge, attitude and practice on tuberculosis prevention and control in parts of Jiangsu Province. Jiangsu J Prev Med 2012;23:1-3.

29. Yu BZ, Yuan YL, Zhang TJ. Current status on knowledge' Attitude and practice of tuberculosis prevention and control in the residents of Jilin province. Chin J Public Health Eng 2014;13:400-2.

30. He GX, Zhou L, Xu M, et al. Implementing DOTS strategy through tuberculosis clubs. Int J Tuberc Lung Dis 2005;9:S135-6.

31. Harries A, Kenyon T, Maher D, et al. "Community TB care in Africa". a collaborative project coordinated by WHO. Report on a "lessons learned" meeting in Harare, Zimbabwe, 27-29 September 2000.

32. Department of diseases control, $\mathrm{MOH}, \mathrm{MOH}$ Foreign Loan Office and Chinese center of Disease control and prevention. Health promotion toolkit of Chinese TB control and prevention. 2005.

33. Saha A, Poddar E, Mankad M. Effectiveness of different methods of health education: a comparative assessment in a scientific conference. BMC Public Health 2005;5:88.

34. Ying L, Cao J, Lin $\mathrm{H}$, et al. Community health needs assessment with precede-proceed model: a mixed methods study. BMC Health Serv Res 2009;9:181.

35. Ma E, Ren L, Wang W, et al. Demographic and socioeconomic disparity in knowledge about tuberculosis in Inner Mongolia, China. $J$ Epidemiol 2015;25:312-20

36. Zhao Y, Ehiri J, Li D, et al. A survey of TB knowledge among medical students in Southwest China: is the information reaching the target? BMJ Open 2013;3:e003454.

37. Wu B, Zhang S, Huang L, et al. A survey on TB knowledge among 620 rural residents in Chongqing. Chongqing Med 2015;44:1112-14

38. Li Y, Ehiri J, Hu D et al. Framework of behavioral indicators evaluating TB health promotion outcomes: a modified Delphi study of TB policymakers and health workers. Infect Dis Poverty 2015;4:56.

39. Sranacharoenpong K, Hanning RM. Developing a diabetes prevention education programme for community health-care workers in Thailand: formative findings. Prim Health Care Res Dev 2011;12:357-69.

40. Ahmed SM, Hossain A, Khan MA, et al. Using formative research to develop $\mathrm{MNCH}$ programme in urban slums in Bangladesh: experiences from MANOSHI, BRAC. BMC Public Health 2010;10:663.

41. Schillinger D. An Introduction to effectiveness, dissemination and implementation research. In: P. Fleisher, E. Goldstein, eds. From the Series: UCSF Clinical and Translational Science Institute (CTSI) Resource Manuals and Guides to Community-Engaged Research, $P$. Fleisher, ed. Clinical Translational Science Institute Community Engagement Program, University of California San Francisco, 2010. http://ctsi.ucsf.edu/files/CE/edi_introguide.pdf

42. Newman SD, Gillenwater G, Toatley S, et al. A community-based participatory research approach to the development of a Peer Navigator health promotion intervention for people with spinal cord injury. Disabil Health J 2014;7:478-84. 